\title{
The future of health care: going to the dogs?
}

\author{
William D. Freeman ${ }^{1,2,3 *}$ and Kenneth A. Vatz ${ }^{4}$ \\ ${ }^{1}$ Department of Neurology, Mayo Clinic, Jacksonville, FL, USA, ${ }^{2}$ Department of Neurosurgery, Mayo Clinic, Jacksonville, FL, \\ USA, ${ }^{3}$ Department of Critical Care, Mayo Clinic, Jacksonville, FL, USA, ${ }^{4}$ CommunityHealth, Chicago, IL, USA
}

Keywords: healthcare costs, non-human employees, nosocomial infections, C. difficile, epilepsy, non-epileptic seizures, canines, animal rights

Escalating healthcare expenditures, which already represent $16 \%$ of the US' gross domestic product (GDP), necessitate redesign of contemporary health care delivery modalities. One such model uses non-human employees (NHE) such as the Canis domesticus, which can potentially lower costs, provide sensitive detection of nosocomial pathogens, alert physicians and other caregivers to impending seizures, and provide comfort to patients. We propose consideration of canine NHE for appropriate clinical situations, but acknowledge the various limitations and caveats.

\section{Perspective}

OPEN ACCESS

Edited by:

David Likosky,

Evergreen Hospital Medical Center,

USA

Reviewed by:

Joshua P. Klein,

Brigham and Women's Hospital, USA Jose Javier Provencio,

Cleveland Clinic, USA

*Correspondence:

William D. Freeman

freeman.william1@mayo.edu

Specialty section:

This article was submitted to Neurocritical and Neurohospitalist Care, a section of the journal Frontiers in Neurology

Received: 12 December 2014 Accepted: 09 April 2015 Published: 08 May 2015

Citation: Freeman WD and Vatz KA (2015) The future of health care: going to the

dogs?

Front. Neurol. 6:87.

doi: 10.3389/fneur.2015.00087
"Outside of a dog, a book is a man's best friend. Inside of a dog it's too dark to read."

- Groucho Marx.

Healthcare expenditures comprise approximately $16 \%$ of the US GDP (1). Escalating costs have necessitated the redesign of contemporary health care delivery models in order to drive down costs and provide high-quality care. We propose one such model, which is utilizing "non-human employees" in healthcare. One indisputable example of underutilized NHE is the C. domesticus, colloquially referred to as "man's best friend." Canine NHE can be relatively low-cost alternatives to human employees (HE), with an initial capital expense on the order of \$500-\$2000 US [although the cost of obtaining a service dog can be as much as $\$ 30,000$ US (2)], and between $\$ 1100$ and $\$ 3500$ US annually in maintenance (Figure 1) (3). Canine NHE may be more cost-effective when rescued from humane societies or other local repositories, and arguably constitute a tax-deductible expense for health care businesses.

At first blush, skeptics might have doubts regarding existing evidence supporting a canine NHE model. There is, in fact, considerable literature validating canine NHE use in healthcare. First, canines have been shown to be effective in detecting harmful hospital pathogens such a Clostridium difficile infection $(4,5)$, which can add considerable length of stay and cost for treating the disorder. Canine olfactory power is estimated to be up to 6 million times stronger than the human nose, thereby adding a tremendous biologic sensor in hospitals to detect $C$. difficile toxin $(4,5)$. C. difficile infection is an important nosocomial pathogen and a common cause of hospital diarrhea. The costs for management of $C$. difficile infection are estimated at around $\$ 800$ million in USA and $€ 3000$ million in Europe annually (5). Second, canine counterparts may improve the physical and psychological health of humans, especially those with disabilities $(6,7)$. Third, canines may play a role in the detection of certain health problems in humans, including cancer, epileptic seizures (ES), and hypoglycemia (6). Even the Journal of the American Medical Association (JAMA) published an issue with cover artwork (Dogs Playing Doctor) paying homage to the early twentieth century artist Cassius Marcellus Coolidge (8). 


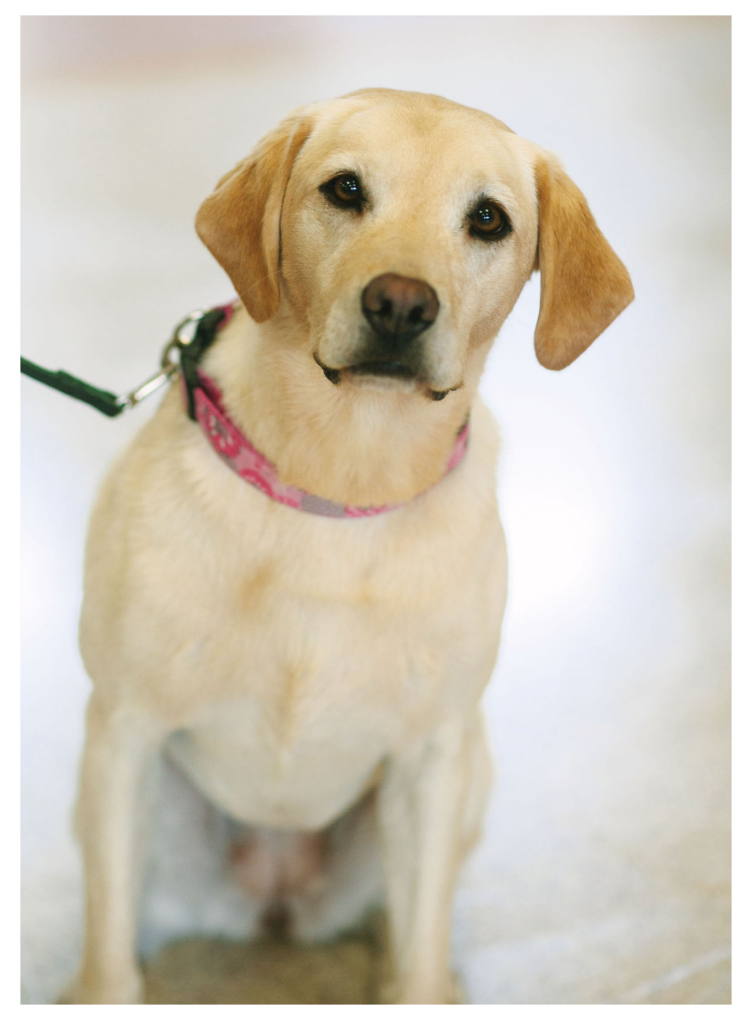

FIGURE 1 | The figure displays a potential candidate for an NHE program involved in the Mayo "Caring canines" program, which is a service in which canines visit hospitalized patients for psychological well-being. This dog is calm, obedient, and well-mannered. While this candidate is a yellow Labrador, canine NHE are available in different breeds, sizes, and temperaments.

\section{References}

1. Munoz E, Munoz W III, Wise L. National and surgical health care expenditures, 2005-2025. Ann Surg (2010) 251:195-200. doi:10.1097/SLA.0b013e3181cbcc9a

2. Service Dogs - Paws with a Cause (2013). Available from: https://www. pawswithacause.org/i-want-a-dog/service-dogs

3. The Cost of Dog Ownership. About.com (2015). Available from: http://dogs. about.com/od/becomingadogowner/a/costofdogs.htm

4. Bomers MK, van Agtmael MA, Luik H, van Veen MC, Vandenbroucke-Grauls CM, Smulders YM. Using a dog's superior olfactory sensitivity to identify Clostridium difficile in stools and patients: proof of principle study. BMJ (2012) 345:e7396. doi:10.1136/bmj.e7396

5. Bouza E. Consequences of Clostridium difficile infection: understanding the healthcare burden. Clin Microbiol Infect (2012) 18(Suppl 6):5-12. doi:10.1111/ 1469-0691.12064

6. Wells DL. Dogs as a diagnostic tool for ill health in humans. Altern Ther Health Med (2012) 18:12-17.

7. Winkle M, Crowe TK, Hendrix I. Service dogs and people with physical disabilities partnerships: a systematic review. Occup Ther Int (2012) 19:54-66. doi:10.1002/oti.323

8. Cover. JAMA (2013) 310(21):2213-356.

9. Ortiz R, Liporace J. "Seizure-alert dogs": observations from an inpatient video/ EEG unit. Epilepsy Behav (2005) 6:620-2. doi:10.1016/j.yebeh.2005.02.012
Canine NHE have been proposed for the detection of ES (9). The role, however, for their detection remains uncertain, and the tendency to identify non-epileptic seizures (NES) during video-electroencephalographic (EEG) monitoring has been a confounding factor $(10,11)$. To date, the results have been mixed in terms of sensitivity and specificity to both patients with ES and NES and regarding the ability of canine NHE to distinguish between the two types of events. Regardless of the pathophysiology, NHE also provide a degree of psychological comfort to patients (11-13).

Therefore, we propose that canine NHE be considered in future health care delivery models as a potential value added measure, even considering the additional ongoing expenses of the consistent human companionship required for canines working in these roles. For many of these functions, such as prescribing and administering medications, canines still cannot replace human care givers. It must be emphasized, however, that the benefits of canine NHE go beyond the mechanics of care giving, in that they unquestionably provide companionship and much emotional support for both human health care employees and patients. Of course, as NHE become more prevalent, animal rights groups are expected to advocate for such canines to seek legal "personhood" similar to that of chimpanzees (14), thus potentially reducing their adoption into health care use due to increased overhead and administrative costs.

\section{Acknowledgments}

The authors acknowledge and thank Ms. Victoria L. Jackson, MLIS, ELS, for her editorial assistance and Dr. William O. Tatum for his assistance with literature on canines for epilepsy.

10. Krauss GL, Choi JS, Lesser RP. Pseudoseizure dogs. Neurology (2007) 68:308-9. doi:10.1212/01.wnl.0000250345.23677.6b

11. Doherty MJ, Haltiner AM. Wag the dog: skepticism on seizure alert canines. Neurology (2007) 68:309. doi:10.1212/01.wnl.0000252369.82956.a3

12. Kirton A. Pseudoseizure dogs. Neurology (2007) 68:2045. doi:10.1212/01.wnl. 0000268590.95483 .74

13. Litt B, Krieger A. Of seizure prediction, statistics, and dogs: a cautionary tail. Neurology (2007) 68:250-1. doi:10.1212/01.wnl.0000255912.43452.12

14. Lawsuits Could Turn Chimpanzees into Legal Persons (2014). Available from: http://news.sciencemag.org/plants-animals/2013/12/lawsuits-could-turnchimpanzees-legal-persons?utm_source=buffer\&utm_campaign=Buffer\&utm content=buffer320d2\&utm_medium=twitter

Conflict of Interest Statement: The authors declare that the research was conducted in the absence of any commercial or financial relationships that could be construed as a potential conflict of interest.

Copyright $\odot 2015$ Freeman and Vatz. This is an open-access article distributed under the terms of the Creative Commons Attribution License (CC BY). The use, distribution or reproduction in other forums is permitted, provided the original author(s) or licensor are credited and that the original publication in this journal is cited, in accordance with accepted academic practice. No use, distribution or reproduction is permitted which does not comply with these terms. 